\title{
Usual source of care and the quality of primary care: a survey of patients in Guangdong province, China
}

\author{
Zhicheng Du', Yu Liao ${ }^{1}$, Chien-Chou Chen ${ }^{3}$, Yuantao Hao ${ }^{1}$ and Ruwei $\mathrm{Hu}^{2 *}$
}

\begin{abstract}
Introduction: Usual source of care (USC) refers to the provider or place a patient consults when sick or in need of medical advice. No studies have been conducted in China to compare the quality of primary care provided with or without USC. The purpose of this study was to fill this gap in the literature by examining the quality of primary care provided between those having a USC and those without. Results of the study would provide implications for policymakers in terms of improving primary care performance in China, and help guide patients in their health care seeking behaviors.

Methods: A cross-sectional survey with patients was conducted in Guangdong province of China, using the Chinese validated Primary Care Assessment Tool (PCAT). ANOVA was performed to compare the overall and ten domains of primary care quality for patients with and without USC. Multivariate analyses were used to assess the association between USC and quality of primary care attributes while controlling for sociodemographic and health care characteristics.
\end{abstract}

Results: The study added evidence that having a USC can provide higher quality of primary care to patients than those without a USC. Results of this study showed that the PCAT score associated with those having a USC was significantly higher than those not having a USC. Moreover, the study showed that having a usual provider of care was also independently and significantly associated with patients' satisfaction with care.

Conclusions: This study added evidence that in China, patients with a USC reported higher quality of medical care experiences compared with those without a USC. The efforts to improve quality of care should include policies promoting USC.

Keywords: Usual source of care, Primary care, Quality of care, Community health centers

\section{Introduction}

Usual source of care (USC) is one of the hallmarks of primary care. It refers to the provider or place a patient consults when sick or in need of medical advice [1]. Internationally, a large body of research indicates that USC could reduce hospitalization cost [2], provide more effective and equitable care [3], increase vaccination coverage [4], enhance timely access to medical care, and improve quality of care received. Studies have also been conducted to examine the effects of USC and

\footnotetext{
* Correspondence: huruwei@mail.sysu.edu.cn

2Department of health management, School of Public Health, Sun Yat-sen University, 74 Zhongshan Road II, Guangzhou, Guangdong Province 510080 Peoples Republic of China

Full list of author information is available at the end of the article
}

demonstrated that USC contributes to better health outcomes [5-7]. The link between USC and quality of care may be explained by the presence of patient-centered care, which is more likely to occur when physicians establish continuing relationships with their patients $[8,9]$. The continuing relationship ensures better knowledge of patients as persons rather than symptoms, enhances communication, and reduces chances for conflicts and misunderstandings. Moreover, patient selection of USC has also been associated with higher levels of patient satisfaction with care [10] and a satisfied patient is more likely to follow up with physician orders.

China has a three-tiered health care delivery system, with the primary care system at the bottom, secondary 
hospitals in the middle, and tertiary hospitals at the top $[11,12]$. Despite this classification, patients can access primary care in all facilities across the three levels, having the freedom to choose a doctor or health care facility without the constraints of health insurance policy [13]. Most people prefer higher-level hospitals due to better medical technology and perceived technical quality of the provider, although they will not see the same doctor each time. However, higher-level hospitals require registering in a long queue, which has a significant time constraint. This also means that doctors have less time to treat and interact with their patients. This may result in unsatisfactory experience of care, as patients often complain that their doctors hustle them through appointments.

Studies examining the relationship between USC and quality of care have been conducted primarily in the USA [14-21] and Taiwan [22]. These studies have shown that USC is significantly associated with patients' experience and perceived quality of care. However, it has been difficult to ascertain whether the observed effects on quality of medical care experiences are in fact due to USC or insurance coverage since many insurance plans require their subscribers to use a USC.

China has been undergoing health care reform, and community health centers $(\mathrm{CHCs})$ are being established as the preferred primary care providers. $\mathrm{CHCs}$ make it easier to access a health care provider that may become a USC. Whether this model is able to improve quality of care has come into question. No studies have been conducted in China to compare the quality of primary care provided with or without USC. In Guangdong province, China, a new policy around a family physician model was carried out as a pilot project in that patients are encouraged to sign up with a family physician as their USC. It is necessary to examine the relationship between USC and the quality of primary care in China to provide evidence that USC matters when it comes to delivering quality care and enhance patient satisfaction.

The purpose of this study was to fill this gap in the literature by examining the quality of primary care provided between those having a USC and those without. Results of the study would provide implications for policymakers in terms of improving primary care performance in China, and help guide patients in their health care seeking behaviors and improve provider-patient relationship.

\section{Methods}

\section{Study setting and design}

The study was carried out in Guangdong province of southern China, which is adjacent to Hong Kong and Macau. The population of permanent residents in Guangdong province is more than 100 million, making it the most populous province in China. Variable economic and geographic development makes Guangdong a good case study for China. We conducted a cross-sectional survey with patients who may visit the same doctor/ place or shop around different providers when seeking routine medical treatment. The sample size was calculated based on findings from a previous paper that compared the primary care scores between patients at health maintenance organizations and patients at community health centers [23]. The minimum sample size of this study was estimated as 800 with a $95 \%$ confidence interval and a power of $80 \%$.

A multistage cluster sampling method was adopted. In the first stage, all 21 cities in Guangdong province were categorized into two levels according to the per capita GDP-developed and developing city. In each level, we randomly selected two cities. In each city, we included 200 patients. In the second stage, we stratified between rural and urban areas. In rural areas, we enrolled patients in county hospitals and rural $\mathrm{CHCs}$, while in urban areas we enrolled patients in tertiary hospitals, secondary hospitals and urban CHCs. Thus, there were 50 patients enrolled from each type of health care facility.

Researchers from the School of Public Health of Sun Yat-sen University in Guangdong, China, conducted the primary data collection. Informed consent was obtained from all participating study subjects. The Institutional Review Board (IRB) of Sun Yat-sen University reviewed and approved the protocol of the study in compliance with the Declaration of Helsinki-Ethical Principles for Medical Research Involving Human Subjects (Approval No.: IRB2014.9).

This was a cross-sectional survey using a face-to-face questionnaire administrated by interviewers trained to collect data. The survey was conducted from November 2013 to September 2014. The subject inclusion criteria were as follows: 1) The patient received primary care from the health care facility, 2) The patient usually chose the study site to get primary care if needed, and 3) The patient read the informed consent and agreed to participate in the investigation. The exclusion criteria were as follows: 1) The patient was in poor physical condition and could not complete the survey, or 2) that the patient could not understand the questionnaire.

\section{Measures}

We used the Chinese validated Primary Care Assessment Tool (PCAT) Adult and Child Editions for data collection [24] The PCAT was developed by the Johns Hopkins Primary Care Policy Center to measure the extent and quality of primary care services in provider settings, and is consistent with a focus on attributes of primary care that have been demonstrated to produce better outcomes of care at lower costs [25]. On average, 
each questionnaire required $20 \mathrm{~min}$ to complete. Rather than ratings of satisfaction, PCAT scores objectively measure patients' experiences with primary care [24].

\section{Usual source (provider and place) of care}

We used two questions in our questionnaire to identify patients with a USC (provider and place): 1) Will you visit the same doctor when you are sick or need advice about your health? 2) Is this facility an appointed medical institution for you?

\section{Primary care quality}

The validated PCAT consists of ten scales representing seven primary care domains: first contact (i.e., access and utilization), longitudinality (i.e., ongoing care), coordination (i.e., referrals and information systems), comprehensiveness (i.e., services available and provided), family centeredness, community orientation, and cultural competence. First contact care implies accessibility to and use of services for each new problem or new episode of a problem for which people seek health care. Longitudinality presupposes the existence of a regular source of care and the characteristics of the interpersonal relationship between that source and the patient. Coordination of care requires some form of continuity, either by practitioners, medical records, or both, as well as recognition of problems that are addressed elsewhere and the integration of their care into the total care of patients. Comprehensiveness implies that primary care facilities must be able to provide or arrange for all types of health care services, including referrals to secondary services for consultation, tertiary services for specific conditions, and essential supporting services such as home care and other community services [26]. Family centeredness, community orientation, and cultural competence refer to the provider's knowledge of community needs and involvement in the community. These primary care domains are consistent with the US Institute of Medicine's definition of primary care [27, 28].

For consistency in response and scoring, all items were represented by a Likert-type scale with 1 indicating "Definitely Not," 2 indicating "Probably Not," 3 indicating "Probably," 4 indicating "Definitely," and 9 indicating "Not sure." The sum score for each domain was derived by summing (after reverse-coding where appropriate, 9 was coded with 2.5) the values for all the items under each domain. The sum score for overall quality of primary care experience was derived by summing the values for all domains.

\section{Satisfaction with care}

Satisfaction with care was the outcome in our study. It was coded as a 5-point Likert scale with 1 indicating "very satisfied," 2 indicating "satisfied," 3 indicating "average," 4 indicating "dis-satisfied," and 5 indicating "very dis-satisfied." To simplify the interpretation of results, we collapsed the responses into two categories: satisfied (including 1 and 2) and dis-satisfied (including 3,4 and 5).

\section{Sociodemographic and health status}

The questionnaire included questions about various sociodemographic characteristics (i.e., gender, age, marriage, rural or urban, household registration, education, occupation, household income) and health status (i.e., self-perceived health status, whether respondent had any physical or mental concerns that lasted for 1 year or longer).

\section{Analysis}

The overall aim of the analysis was to compare the quality of primary care experienced by patients with a USC versus those without a USC. First, we used chi-square to compare sociodemographic and health characteristics of patients with and without a USC. Next, we used paired t-tests to compare quality of primary care indicators for patients with and without a USC. Multiple linear regression models were then used to assess the association between USC and quality of primary care attributes after controlling for patients' sociodemographic and health characteristics, as well as the type of health care facility. Patient characteristics were included as control variables to account for differences that may lead some patients to choose a USC and others to shop around. Separate models were created for each primary care domain, as well as for overall quality of care. Similarly, two logistic regression models were used to assess the association between satisfaction and USC and overall quality of primary care with and without controlling for the same variables of the multiple linear regression model.

\section{Results}

\section{Sample characteristics}

Table 1 summarizes the general characteristics of the study sample. About half of the respondents were from $\mathrm{CHCs}$ (53.13 \%). Most respondents were female $(59.14 \%)$ and between the ages of 18 and 44 years old $(43.52 \%)$. Seventy percent of the respondents were married. More than half of the respondents were from urban area (59 \%) and had household registration (53.7\%). About half of the respondents had junior education or lower (47.35\%). Half were unemployed or retired, and $60 \%$ reported an average household income per month, per person between RMB $¥ 1350$ and $¥ 4560$ (US $\$ 220-\$ 745)$. The majority (76.5\%) of patients reported that they did not have any physical or mental problems, and a significant group (40.16\%) self-assessed their health status as poor. 
Table 1 Demographic, socioeconomic, and health measures of respondents in Guangdong Province by type of usual source of care

\begin{tabular}{|c|c|c|c|c|c|}
\hline & Total & $\begin{array}{l}\text { Usual provider of } \\
\text { care }=\text { Yes }\end{array}$ & $\begin{array}{l}\text { Usual provider of } \\
\text { care }=\text { No }\end{array}$ & $\begin{array}{l}\text { Usual place of } \\
\text { care = Yes }\end{array}$ & $\begin{array}{l}\text { Usual place of } \\
\text { care = No }\end{array}$ \\
\hline & $(796-864)$ & $(441-471)$ & (355-393) & $(474-500)$ & $(322-364)$ \\
\hline & $N(\%)$ & $N(\%)$ & $N(\%)$ & $N(\%)$ & $N(\%)$ \\
\hline \multicolumn{6}{|l|}{ Facility**, ${ }^{* * * *}$} \\
\hline $\mathrm{CHC}$ & 459(53.13) & 251(53.29) & $208(52.93)$ & $303(60.6)$ & $156(42.9)$ \\
\hline Secondary hospital & $241(27.89)$ & $114(24.2)$ & $127(32.32)$ & $116(23.2)$ & $125(34.3)$ \\
\hline Tertiary hospital & 164(18.98) & $106(22.51)$ & $58(14.76)$ & $81(16.2)$ & $83(22.8)$ \\
\hline \multicolumn{6}{|l|}{ Gender ${ }^{* *}, * * *$} \\
\hline Female & $511(59.14)$ & $300(63.69)$ & 211(53.69) & $313(62.6)$ & $198(54.4)$ \\
\hline Male & $353(40.86)$ & $171(36.31)$ & 182(46.31) & 187(37.4) & $166(45.6)$ \\
\hline \multicolumn{6}{|l|}{$\operatorname{Age}^{* *}, * * * *$} \\
\hline$<18$ & $125(14.47)$ & $66(14.01)$ & $60(15.27)$ & $48(9.6)$ & $78(21.4)$ \\
\hline $18-44$ & $237(27.43)$ & 184(39.07) & 192(48.85) & 183(36.6) & 193(53) \\
\hline $45-64$ & $376(43.52)$ & $140(29.72)$ & $97(24.68)$ & $165(33)$ & $72(19.8)$ \\
\hline$\geq 65$ & 126(14.58) & $81(17.2)$ & $44(11.2)$ & 104(20.8) & $21(5.8)$ \\
\hline \multicolumn{6}{|l|}{ Marriage $e^{* * *}$} \\
\hline Single & $261(30.21)$ & 143(30.36) & 118(30.03) & $127(25.4)$ & 134(36.8) \\
\hline Married & $603(69.79)$ & $328(69.64)$ & 275(69.97) & $373(74.6)$ & $230(63.2)$ \\
\hline \multicolumn{6}{|l|}{ City class** } \\
\hline Rural & $351(40.63)$ & 155(32.91) & 196(49.87) & 199(39.8) & 152(41.8) \\
\hline Urban & $513(59.38)$ & $316(67.09)$ & 197(50.13) & $301(60.2)$ & $212(58.2)$ \\
\hline \multicolumn{6}{|l|}{ Registered ${ }^{* * * *}$} \\
\hline No & $400(46.3)$ & $222(47.13)$ & 178(45.29) & 167(33.4) & $233(64.01)$ \\
\hline Yes & $464(53.7)$ & $249(52.87)$ & $215(54.71)$ & $333(66.6)$ & 131(35.99) \\
\hline \multicolumn{6}{|l|}{ Education } \\
\hline Junior or below & $402(47.35)$ & 219(47.2) & 183(47.53) & 244(49.6) & $158(44.3)$ \\
\hline Senior & 168(19.79) & $95(20.47)$ & $73(18.96)$ & $88(17.9)$ & $80(22.4)$ \\
\hline Technical college & $182(21.44)$ & $92(19.83)$ & $90(23.38)$ & 98(19.9) & $84(23.5)$ \\
\hline Undergraduate or above & $97(11.43)$ & $58(12.5)$ & $39(10.13)$ & $62(12.6)$ & $35(9.8)$ \\
\hline \multicolumn{6}{|l|}{ Occupation*,*** } \\
\hline Unemployed & $438(50.69)$ & 258(54.78) & $180(45.8)$ & $255(51)$ & 183(50.3) \\
\hline Farmer & 101(11.69) & $46(9.77)$ & $55(13.99)$ & $71(14.2)$ & $30(8.2)$ \\
\hline Working in urban & $325(37.62)$ & $167(35.46)$ & $158(40.2)$ & 174(34.8) & $151(41.5)$ \\
\hline \multicolumn{6}{|l|}{ Income ${ }^{* * *}$} \\
\hline Low $(\leq \mathrm{RMB} ¥ 1350)$ & $160(20.1)$ & $77(17.46)$ & $83(23.38)$ & $107(22.57)$ & $53(16.46)$ \\
\hline Median (RMB $¥ 1350-¥ 4560$ ) & $475(59.67)$ & $269(61.00)$ & $206(58.03)$ & $282(59.49)$ & 193(59.94) \\
\hline High ( $\geq$ RMB $¥ 4560$ ) & $161(20.23)$ & $95(21.54)$ & $66(18.59)$ & $85(17.93)$ & $76(23.60)$ \\
\hline \multicolumn{6}{|l|}{ Health status*, ${ }^{* * * *}$} \\
\hline Less than good & $347(40.16)$ & $206(43.74)$ & $141(35.88)$ & $226(45.2)$ & 121(33.2) \\
\hline Equal or greater than good & $517(59.84)$ & $265(56.26)$ & $252(64.12)$ & $274(54.8)$ & $243(66.8)$ \\
\hline \multicolumn{6}{|l|}{ Physical/mental problem ${ }^{* *}, * * * *$} \\
\hline No & $661(76.5)$ & $343(72.82)$ & 318(80.92) & $359(71.8)$ & $302(83)$ \\
\hline Yes & $203(23.5)$ & $128(27.18)$ & 75(19.08) & $141(28.2)$ & $62(17)$ \\
\hline
\end{tabular}


Turning to the quality of care indicators shown in Table 2, the highest average score across all patients was in cultural competence (mean $=3.22$ ), followed by utilization (3.05), family centeredness (3.01), coordination of information systems (3), comprehensiveness of services available (2.99), comprehensiveness of services provided (2.86), coordination of referrals (2.77), access (2.75), ongoing care (2.67), and community orientation (2.06).

\section{Comparing patients with and without a USC}

Comparisons between patients with and without a USC are shown in Table 1. More than half of patients reported having a USC, with $54 \%$ reporting a provider as a USC and $55 \%$ reporting a place as a USC. When considering patients with a provider as a USC, versus patients with no usual provider of care, a greater proportion of patients came from $\mathrm{CHCs}$, were female, between 18 to 44 years of age, reported living in urban areas, were unemployed or retired, did not have poor health status or a physical or mental problem, and reported having a usual provider of care. Similarly, when considering patients with a usual place of care, versus patients with no usual place of care, a greater proportion of patients came from $\mathrm{CHCs}$, were female, between 18 to 44 years of age, married, held household registration, were unemployed or retired, had a median level average household income per month, per person, and did not report poor health status or a physical or mental problem (Table 1).

Looking at quality of care indicators in Table 2, patients with a usual provider of care consistently rated their quality of medical experiences significantly higher than those without a usual provider of care $(P<0.05)$, with the exception of comprehensiveness of services available and family centeredness. When considering a usual place of care, patients rated their quality of medical experiences significantly higher than those without a usual provider of care $(P<0.05)$, except for comprehensiveness of services available.

The radar chart displayed in Fig. 1 shows more detail about the quality of primary care between having and not having a USC. It is apparent that overall, having a usual provider of care was associated with a higher PCAT score than not having one. Figure 1 also provides detailed information on each sub-domain. Having a usual provider of care was associated with a higher score on each sub-domain, particularly first contact utilization, first contact access, ongoing care, coordination referrals, coordination information systems, comprehensiveness service, community orientation and cultural competence. Moreover, Fig. 1 shows that the scoring gap between having a usual provider of care and not having a usual provider of care in the ongoing care sub-domain was the largest, with scores of 2.95 and 2.33 respectively. Figure 2 reveals a similar pattern about usual place of care. Overall, having a usual place of care was associated with a higher PCAT score than not having one. Moreover, patients with a usual place of care scored higher in each subdomain, with the exception of the family centeredness and cultural competence sub-domains. Likewise, the ongoing care sub-domain had the largest difference (0.27) between those with a usual place of care and those without.

\section{USC and other predictors of primary care quality}

Tables 3 and 4 displays the multiple linear regression coefficients for the association between USC and the ten medical care quality indicators, as well as the PCAT summary score representing overall quality of care,

Table 2 Individual and total primary care attributes scores reported by respondents by type of usual source of care

\begin{tabular}{|c|c|c|c|c|c|}
\hline & Total & $\begin{array}{l}\text { Usual provider of } \\
\text { care }=\text { Yes }\end{array}$ & $\begin{array}{l}\text { Usual provider of } \\
\text { care = No }\end{array}$ & $\begin{array}{l}\text { Usual place of } \\
\text { care = Yes }\end{array}$ & $\begin{array}{l}\text { Usual place of } \\
\text { care = No }\end{array}$ \\
\hline First contact (utilization)*, **** & $3.05 \pm 0.64$ & $3.1 \pm 0.64$ & $3 \pm 0.64$ & $3.14 \pm 0.64$ & $2.93 \pm 0.63$ \\
\hline First contact (access) $)^{* *}, * * * *$ & $2.75 \pm 0.71$ & $2.82 \pm 0.68$ & $2.67 \pm 0.73$ & $2.86 \pm 0.69$ & $2.6 \pm 0.71$ \\
\hline Ongoing care ${ }^{* *}, * * * *$ & $2.67 \pm 0.75$ & $2.95 \pm 0.66$ & $2.33 \pm 0.71$ & $2.78 \pm 0.75$ & $2.51 \pm 0.72$ \\
\hline Coordination (referrals) ${ }^{* *}, * * *$ & $2.77 \pm 0.68$ & $2.85 \pm 0.69$ & $2.68 \pm 0.67$ & $2.83 \pm 0.73$ & $2.7 \pm 0.61$ \\
\hline Coordination (information systems) ${ }^{* *}, * * *$ & $3 \pm 0.67$ & $3.12 \pm 0.64$ & $2.85 \pm 0.69$ & $3.1 \pm 0.62$ & $2.86 \pm 0.71$ \\
\hline Comprehensiveness (services available) ${ }^{* * * *}$ & $2.99 \pm 0.56$ & $3.02 \pm 0.58$ & $2.95 \pm 0.54$ & $3.05 \pm 0.55$ & $2.89 \pm 0.57$ \\
\hline Comprehensiveness (services provided) ${ }^{* *}, * * *$ & $2.86 \pm 0.76$ & $2.94 \pm 0.75$ & $2.76 \pm 0.76$ & $2.91 \pm 0.78$ & $2.79 \pm 0.72$ \\
\hline Family centeredness & $3.01 \pm 0.9$ & $3.05 \pm 0.91$ & $2.95 \pm 0.9$ & $3.05 \pm 0.92$ & $2.94 \pm 0.88$ \\
\hline Community orientation ${ }^{* *}, * * * *$ & $2.06 \pm 0.82$ & $2.13 \pm 0.84$ & $1.97 \pm 0.79$ & $2.15 \pm 0.84$ & $1.95 \pm 0.78$ \\
\hline Cultural competence ${ }^{* *}$ & $3.22 \pm 0.65$ & $3.3 \pm 0.64$ & $3.11 \pm 0.65$ & $3.24 \pm 0.66$ & $3.19 \pm 0.64$ \\
\hline PCAT total $\left.\right|^{* *}, * * * *$ & $28.37 \pm 4.52$ & $29.28 \pm 4.39$ & $27.28 \pm 4.42$ & $29.11 \pm 4.57$ & $27.35 \pm 4.24$ \\
\hline
\end{tabular}

${ }^{*} P<.05 .{ }^{* *} P<.01$, based on $t$ test of difference between usual provider of care

${ }^{* * *} P<.05$. ${ }^{* * * *} P<.01$, based on $t$ test of difference between usual place of cares 


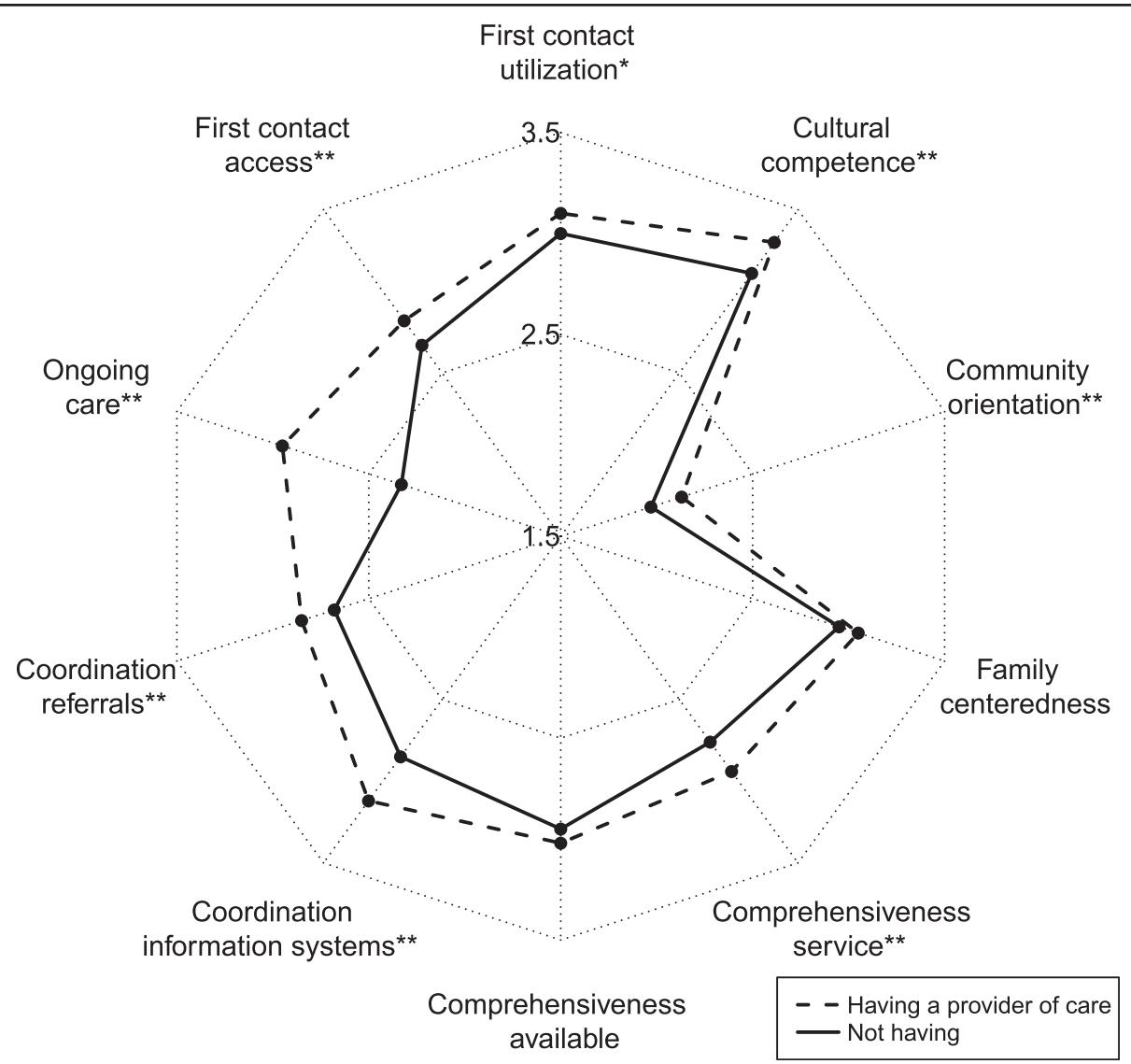

Fig. 1 Usual provider of care and primary care attributes. Having a usual provider of care was associated with a higher score on each sub-domain, particularly first contact utilization, first contact access, ongoing care, coordination referrals, coordination information systems, comprehensiveness service, community orientation and cultural competence. Moreover, the scoring gap between having a usual provider of care and not having a usual provider of care in the ongoing care sub-domain was the largest, with scores of 2.95 and 2.33 respectively

controlling for various socio-demographic, health, and health care characteristics. Patients with a USC reported significantly higher overall quality of medical care experiences than those without a USC (USC Provider: $P<0.01$, USC Place: $P<0.01$ ). Looking at individual quality of care indicators, patients with a usual provider care reported higher quality for all but one indicator $(P<0.05)$. The exception was comprehensiveness of services available, which showed no significant difference between the two groups. Among patients with a usual place care, higher quality was reported for all but two indicators $(P<0.05)$. The exceptions were comprehensiveness of services provided and cultural competence.

In addition to USC, other covariates were also significantly associated with the overall quality of medical care, including facility, gender, education, occupation, household income, health status. Specifically, patients at secondary and tertiary hospital reported lower quality of primary care than those at $\mathrm{CHCs}$; male patients reported lower quality than female; those with technical college education reported higher quality than those with junior or lower education; famers reported higher quality than those who were unemployed; those with higher income reported lower quality than those with lower income; those who self-assessed their health status as poor reported lower quality those self-assessed as good.

\section{Primary care quality, USC, and patient satisfaction}

Table 5 displays the logistic regression results for the association between the PCAT score, USC, and patient satisfaction. We conducted two models. Model 1 controlled for USC, while Model 2 controlled for various sociodemographic, health, and health care characteristics as well as USC. Patients with higher total score $(P<0.01)$ and a USC $(P<0.05)$ reported significantly higher satisfaction. In Model 2, even after controlling other predictors, patients with higher total score $(P<0.01)$ and usual provider of care $(P<0.05)$ continued to report significantly higher satisfaction.

In Model 2, other covariates were also significantly associated with satisfaction, including facility, age, and household registration. Specifically, patients from secondary 


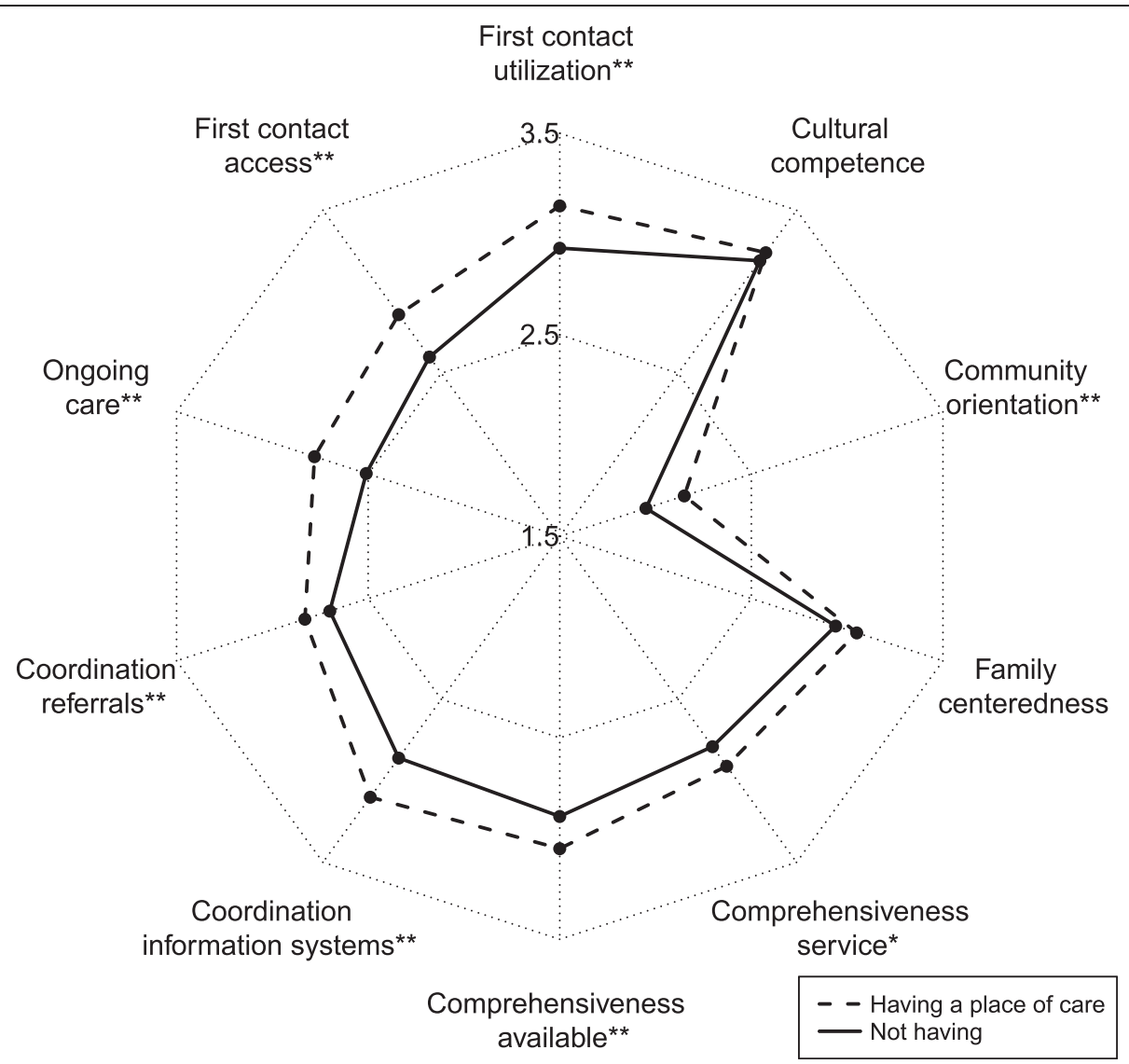

Fig. 2 Usual place of care and primary care attributes. Having a usual place of care was associated with a higher score on each sub-domain, particularly first contact utilization, first contact access, ongoing care, coordination referrals, coordination information systems, comprehensiveness available, comprehensiveness service and community orientation. Moreover, the scoring gap between having a usual place of care and not having a usual place of care in the ongoing care sub-domain was the largest, with scores of 2.78 and 2.51 respectively

hospital reported lower satisfaction than those from $\mathrm{CHCs}$; those younger than 18 reported lower satisfaction than those 65 or older than 65 ; and those with household registration reported higher than those without.

\section{Discussion}

This study used information collected from patient surveys in Guangdong, China, to explore the effects of USC on the quality of primary care using an internationally and locally validated tool, PCAT. The USC refers to the provider or place a patient consults when sick or in need of medical care. The study added evidence that having a USC can provide higher quality of primary care to patients than those without a USC. Results of this study showed that the PCAT score associated with those having a USC was significantly higher than those not having a USC. Specifically, the PCAT total score for those with a usual provider of care was 29.28 , a full two points better than those not having a usual provider of care (27.28). The PCAT total score for those with a usual place of care was 29.11, 1.76 points better than those not having a usual place of care (27.35).

Table 5 shows that, after controlling for other confounders, having a usual provider of care was independently and significantly associated with patients' satisfaction with care, while having a usual place of care was not statistically significant. This suggests that a usual provider of care may be more important than a usual place of care in influencing patients' satisfaction with primary care. Patients who were female, 18-44 years old, married, living in urban areas, in a registered home, had a median income and no physical or mental problems were more likely to search for primary care from a usual provider of care and usual place of care.

Although there has been significant research focusing on the association between USC and medical care in other countries [14-22], research on the topic in China is limited. Results of this study demonstrated that after adjusting for confounders, overall quality of primary care was significantly higher for patients with a USC than those without. Our findings are consistent with previous 
Table 3 Patient and institutional characteristics associated with individual and total primary care attributes

\begin{tabular}{|c|c|c|c|c|c|}
\hline & $\begin{array}{l}\text { First contact } \\
\text { utilization }\end{array}$ & First contact access & Ongoing care & Coordination referrals & $\begin{array}{l}\text { Coordination information } \\
\text { systems }\end{array}$ \\
\hline & Beta(SE) & Beta(SE) & Beta(SE) & Beta(SE) & Beta(SE) \\
\hline Intercept & $3.32^{* *}(0.12)$ & $2.75^{* *}(0.13)$ & $2.46^{* *}(0.12)$ & $2.79^{* *}(0.13)$ & $3.01 * *(0.12)$ \\
\hline \multicolumn{6}{|l|}{ Usual provider of care $(\operatorname{Ref}=$ no) } \\
\hline Yes & $0.1 *(0.04)$ & $0.18^{* *}(0.05)$ & $0.59^{* *}(0.05)$ & $0.2^{* *}(0.05)$ & $0.2^{* *}(0.04)$ \\
\hline \multicolumn{6}{|l|}{ Usual place of care $(\operatorname{Ref}=$ no $)$} \\
\hline Yes & $0.18^{* *}(0.05)$ & $0.23^{* *}(0.05)$ & $0.11^{*}(0.05)$ & $0.11^{*}(0.05)$ & $0.2^{* *}(0.05)$ \\
\hline \multicolumn{6}{|l|}{ Facility $($ Ref $=\mathrm{CHC})$} \\
\hline Secondary hospital & $-0.02(0.05)$ & $-0.14^{* *}(0.06)$ & $-0.22^{* *}(0.06)$ & $-0.11^{*}(0.06)$ & $-0.06(0.05)$ \\
\hline Tertiary hospital & $-0.01(0.06)$ & $-0.09(0.07)$ & $-0.26^{* *}(0.07)$ & $-0.13(0.07)$ & $0.05(0.07)$ \\
\hline \multicolumn{6}{|l|}{ Gender (Ref = female) } \\
\hline Male & $-0.12^{* *}(0.04)$ & $-0.12^{*}(0.05)$ & $-0.03(0.05)$ & $-0.02(0.05)$ & $-0.1^{*}(0.05)$ \\
\hline \multicolumn{6}{|l|}{ Age (Ref = 65 or older $)$} \\
\hline 45 to 64 & $-0.18^{* *}(0.07)$ & $0.03(0.08)$ & $-0.03(0.08)$ & $-0.04(0.08)$ & $-0.16 *(0.08)$ \\
\hline 18 to 44 & $-0.17^{*}(0.08)$ & $0.11(0.09)$ & $-0.07(0.09)$ & $0.005(0.09)$ & $-0.24^{* *}(0.08)$ \\
\hline Younger than 18 & $-0.1(0.1)$ & $0.14(0.11)$ & $-0.21^{*}(0.1)$ & $-0.06(0.11)$ & $-0.24^{*}(0.1)$ \\
\hline \multicolumn{6}{|l|}{ Marriage $($ Ref $=$ single $)$} \\
\hline Married & $0.0004(0.06)$ & $0.03(0.07)$ & $-0.12(0.06)$ & $-0.1(0.07)$ & $-0.11(0.06)$ \\
\hline \multicolumn{6}{|l|}{ City class (Ref = rural) } \\
\hline Urban & $-0.002(0.05)$ & $-0.07(0.06)$ & $0.1(0.06)$ & $-0.04(0.06)$ & $0.13^{*}(0.06)$ \\
\hline \multicolumn{6}{|l|}{ Registered $($ Ref $=$ no $)$} \\
\hline Yes & $-0.02(0.05)$ & $-0.02(0.05)$ & $0.07(0.05)$ & $-0.01(0.05)$ & $-0.04(0.05)$ \\
\hline \multicolumn{6}{|l|}{ Education (Ref $=$ junior or lower) } \\
\hline Senior & $-0.12^{*}(0.06)$ & $-0.0007(0.07)$ & $-0.09(0.06)$ & $0.02(0.06)$ & $0.02(0.06)$ \\
\hline Technical college & $0.07(0.06)$ & $0.18^{* *}(0.07)$ & $0.13^{*}(0.06)$ & $0.16^{* *}(0.07)$ & $0.13^{*}(0.06)$ \\
\hline Undergraduate or above & $-0.02(0.08)$ & $0.13(0.09)$ & $0.03(0.08)$ & $0.02(0.09)$ & $-0.02(0.08)$ \\
\hline \multicolumn{6}{|l|}{ Occupation (Ref $=$ unemployed) } \\
\hline Farmer & $0.07(0.08)$ & $0.23^{* *}(0.08)$ & $0.03(0.08)$ & $0.16^{*}(0.08)$ & $-0.02(0.08)$ \\
\hline Working in urban & $-0.06(0.06)$ & $-0.03(0.06)$ & $-0.09(0.06)$ & $-0.03(0.06)$ & $-0.07(0.06)$ \\
\hline \multicolumn{6}{|l|}{ Income $($ Ref $=$ low $)$} \\
\hline Median & $-0.14^{*}(0.06)$ & $-0.17^{*}(0.07)$ & $-0.03(0.07)$ & $-0.1(0.07)$ & $-0.03(0.07)$ \\
\hline High & $-0.31^{* *}(0.08)$ & $-0.34^{* *}(0.09)$ & $-0.1(0.09)$ & $-0.25^{* *}(0.09)$ & $-0.08(0.08)$ \\
\hline Missing & $-0.28^{* *}(0.09)$ & $-0.31^{* *}(0.1)$ & $-0.48^{* *}(0.1)$ & $-0.27^{* *}(0.1)$ & $-0.28^{* *}(0.1)$ \\
\hline \multicolumn{6}{|c|}{ Health status (Ref $=$ less than good) } \\
\hline Equal or greater than good & $0.04(0.05)$ & $-0.02(0.05)$ & $0.13^{* *}(0.05)$ & $0.16^{* *}(0.05)$ & $0.15^{* *}(0.05)$ \\
\hline \multicolumn{6}{|l|}{ Health problem $(\operatorname{Ref}=$ no) } \\
\hline Yes & $-0.25^{* *}(0.06)$ & $-0.2^{* *}(0.06)$ & $0.02(0.06)$ & $-0.06(0.06)$ & $-0.04(0.06)$ \\
\hline Adjust R squared & 0.09 & 0.10 & 0.26 & 0.06 & 0.11 \\
\hline Sample Size & 864 & 864 & 864 & 864 & 864 \\
\hline
\end{tabular}

${ }^{*} P<.05 .{ }^{* *} P<.01$

studies that have examined the impact of USC on medical quality [14-22].

Although our study evidence suggested that having a USC can improve quality of primary care, this is not yet a requirement in China and the government imposes no restrictions on health care provider selection. Because of this, health resources may not be effectively used, as patients will crowd in tertiary hospital although their 
Table 4 Patient and institutional characteristics associated with individual and total primary care attributes (Cont.)

\begin{tabular}{|c|c|c|c|c|c|c|}
\hline & $\begin{array}{l}\text { Comprehensiveness } \\
\text { available }\end{array}$ & $\begin{array}{l}\text { Comprehensiveness } \\
\text { service }\end{array}$ & $\begin{array}{l}\text { Family } \\
\text { centeredness }\end{array}$ & $\begin{array}{l}\text { Community } \\
\text { orientation }\end{array}$ & $\begin{array}{l}\text { Cultural } \\
\text { competence }\end{array}$ & PCAT total \\
\hline & Beta(SE) & Beta(SE) & Beta(SE) & Beta(SE) & Beta(SE) & Beta(SE) \\
\hline Intercept & $2.94^{* *}(0.1)$ & $2.87^{* *}(0.14)$ & $2.99 * *(0.17)$ & $2.22^{* *}(0.14)$ & $2.91^{* *}(0.12)$ & $28.25^{* *}(0.79)$ \\
\hline \multicolumn{7}{|l|}{$\begin{array}{l}\text { Usual provider of care (Ref } \\
=\text { no) }\end{array}$} \\
\hline Yes & $0.06(0.04)$ & $0.21^{* *}(0.05)$ & $0.15^{*}(0.06)$ & $0.18^{* *}(0.05)$ & $0.17^{* *}(0.04)$ & $2.03^{* *}(0.29)$ \\
\hline \multicolumn{7}{|l|}{$\begin{array}{l}\text { Usual place of care (Ref = } \\
\text { no) }\end{array}$} \\
\hline Yes & $0.14^{* *}(0.04)$ & $0.08(0.06)$ & $0.13^{*}(0.07)$ & $0.11^{*}(0.06)$ & $-0.03(0.05)$ & $1.26^{* *}(0.32)$ \\
\hline \multicolumn{7}{|l|}{ Facility $($ Ref $=\mathrm{CHC})$} \\
\hline Secondary hospital & $-0.25^{* *}(0.05)$ & $-0.12(0.06)$ & $-0.07(0.08)$ & $-0.55^{* *}(0.06)$ & $-0.15^{* *}(0.05)$ & $-1.69^{* *}(0.35)$ \\
\hline Tertiary hospital & $-0.06(0.06)$ & $-0.11(0.08)$ & $0.04(0.09)$ & $-0.53^{* *}(0.08)$ & $-0.04(0.07)$ & $-1.14^{* *}(0.43)$ \\
\hline \multicolumn{7}{|l|}{ Gender (Ref $=$ female) } \\
\hline Male & $-0.08^{*}(0.04)$ & $-0.07(0.05)$ & $-0.11(0.06)$ & $-0.03(0.05)$ & $-0.1 *(0.05)$ & $-0.79^{* *}(0.3)$ \\
\hline \multicolumn{7}{|l|}{ Age (Ref $=65$ or older) } \\
\hline 45 to 64 & $0.02(0.07)$ & $-0.04(0.09)$ & $-0.09(0.1)$ & $-0.07(0.09)$ & $0.04(0.07)$ & $-0.52(0.49)$ \\
\hline 18 to 44 & $0.004(0.07)$ & $-0.05(0.1)$ & $-0.05(0.12)$ & $-0.02(0.1)$ & $-0.03(0.08)$ & $-0.51(0.54)$ \\
\hline Younger than 18 & $0.08(0.09)$ & $-0.18(0.12)$ & $0.18(0.14)$ & $-0.19(0.12)$ & $-0.06(0.1)$ & $-0.64(0.67)$ \\
\hline \multicolumn{7}{|l|}{ Marriage $(\operatorname{Ref}=$ single $)$} \\
\hline Married & $0.01(0.05)$ & $-0.04(0.07)$ & $-0.01(0.09)$ & $-0.15^{*}(0.07)$ & $0.11(0.06)$ & $-0.39(0.41)$ \\
\hline \multicolumn{7}{|l|}{ City class (Ref $=$ rural) } \\
\hline Urban & $-0.1 *(0.05)$ & $-0.06(0.06)$ & $-0.14(0.08)$ & $-0.03(0.07)$ & $-0.06(0.05)$ & $-0.29(0.36)$ \\
\hline \multicolumn{7}{|l|}{ Registered $($ Ref $=$ no) } \\
\hline Yes & $-0.02(0.04)$ & $-0.02(0.06)$ & $-0.06(0.07)$ & $-0.09(0.06)$ & $0.11 *(0.05)$ & $-0.11(0.31)$ \\
\hline \multicolumn{7}{|l|}{$\begin{array}{l}\text { Education }(\text { Ref }=\text { junior or } \\
\text { lower) }\end{array}$} \\
\hline Senior & $0.04(0.05)$ & $0.000001(0.07)$ & $-0.05(0.09)$ & $-0.01(0.07)$ & $-0.002(0.06)$ & $-0.19(0.4)$ \\
\hline Technical college & $0.09(0.05)$ & $0.13(0.07)$ & $0.16(0.09)$ & $0.2^{* *}(0.07)$ & $0.08(0.06)$ & $1.33^{* *}(0.41)$ \\
\hline Undergraduate or above & $0.08(0.07)$ & $0.03(0.1)$ & $0.08(0.11)$ & $0.002(0.1)$ & $-0.02(0.08)$ & $0.33(0.54)$ \\
\hline \multicolumn{7}{|l|}{$\begin{array}{l}\text { Occupation (Ref = } \\
\text { unemployed) }\end{array}$} \\
\hline Farmer & $0.09(0.07)$ & $0.2^{*}(0.09)$ & $0.34^{* *}(0.11)$ & $0.16(0.09)$ & $-0.14(0.08)$ & $1.12^{*}(0.52)$ \\
\hline Working in urban & $0.03(0.05)$ & $0.02(0.07)$ & $0.1(0.08)$ & $-0.03(0.07)$ & $-0.14^{*}(0.06)$ & $-0.29(0.4)$ \\
\hline \multicolumn{7}{|l|}{ Income (Ref = low) } \\
\hline Median & $-0.01(0.06)$ & $-0.06(0.08)$ & $-0.08(0.09)$ & $0.02(0.08)$ & $0.16^{*}(0.07)$ & $-0.46(0.43)$ \\
\hline High & $-0.02(0.07)$ & $-0.2^{*}(0.1)$ & $-0.22(0.12)$ & $-0.24^{*}(0.1)$ & $0.18^{*}(0.08)$ & $-1.6^{* *}(0.55)$ \\
\hline Missing & $0.02(0.08)$ & $-0.14(0.11)$ & $-0.37^{* *}(0.13)$ & $-0.17(0.11)$ & $0.02(0.09)$ & $-2.27^{* *}(0.63)$ \\
\hline \multicolumn{7}{|l|}{$\begin{array}{l}\text { Health status (Ref }=\text { less } \\
\text { than good) }\end{array}$} \\
\hline $\begin{array}{l}\text { Equal or greater than } \\
\text { good }\end{array}$ & $0.08(0.04)$ & $0.15^{* *}(0.06)$ & $0.17^{* *}(0.07)$ & $0.25^{* *}(0.06)$ & $0.24^{* *}(0.05)$ & $1.36^{* *}(0.31)$ \\
\hline \multicolumn{7}{|l|}{ Health problem $(\operatorname{Ref}=$ no) } \\
\hline Yes & $0.06(0.05)$ & $-0.12(0.07)$ & $-0.14(0.08)$ & $0.06(0.07)$ & $0.11(0.06)$ & $-0.56(0.38)$ \\
\hline Adjust R squared & 0.04 & 0.04 & 0.05 & 0.16 & 0.08 & 0.16 \\
\hline Sample Size & 864 & 864 & 864 & 864 & 864 & 864 \\
\hline
\end{tabular}


Table 5 Factors associated with patients' satisfaction with care

\begin{tabular}{|c|c|c|}
\hline & & OR $(95 \% \mathrm{Cl})$ \\
\hline \multirow[t]{8}{*}{ Model 1} & Intercept & $0.02 * *(0.01,0.07)$ \\
\hline & PCAT total & $1.19 * *(1.14,1.25)$ \\
\hline & Usual provider of care $(\operatorname{Ref}=$ no) & \\
\hline & Yes & $1.52 *(1.06,2.18)$ \\
\hline & Usual place of care $(\operatorname{Ref}=\mathrm{no})$ & \\
\hline & Yes & $1.47^{*}(1.03,2.1)$ \\
\hline & Nagelkerke R squared & 0.17 \\
\hline & Sample & 864 \\
\hline \multirow[t]{32}{*}{ Model 2} & Intercept & $0.04^{* *}(0.01,0.22)$ \\
\hline & PCAT total & $1.19 * *(1.14,1.25)$ \\
\hline & Usual provider of care $(\operatorname{Ref}=$ no) & \\
\hline & Yes & $1.48 *(1.01,2.17)$ \\
\hline & Usual place of care $(\operatorname{Ref}=\mathrm{no})$ & \\
\hline & Yes & $1.02(0.68,1.52)$ \\
\hline & Facility $($ Ref $=\mathrm{CHC})$ & \\
\hline & Secondary hospital & $0.48^{* *}(0.32,0.74)$ \\
\hline & Tertiary hospital & $0.78(0.46,1.34)$ \\
\hline & Gender (Ref = female) & \\
\hline & Male & $1.4(0.94,2.09)$ \\
\hline & Age (Ref $=65$ or older $)$ & \\
\hline & 45 to 64 & $0.84(0.38,1.79)$ \\
\hline & 18 to 44 & $0.57(0.25,1.24)$ \\
\hline & Younger than 18 & $0.24^{* *}(0.09,0.6)$ \\
\hline & Marriage $($ Ref $=$ single) & \\
\hline & Married & $0.8(0.45,1.38)$ \\
\hline & Registered $($ Ref $=$ no) & \\
\hline & Yes & $1.55^{*}(1.04,2.31)$ \\
\hline & Education (Ref = junior or lower) & \\
\hline & Senior & $0.94(0.57,1.57)$ \\
\hline & Technical secondary school or college & $1.01(0.6,1.71)$ \\
\hline & Undergraduate or above & $1.25(0.66,2.44)$ \\
\hline & Occupation (Ref = unemployed) & \\
\hline & Farmer & $0.79(0.39,1.64)$ \\
\hline & Working in urban & $0.92(0.56,1.53)$ \\
\hline & Health status (Ref = less than good) & \\
\hline & Equal or greater than good & $1.37(0.91,2.06)$ \\
\hline & Health problem $(\operatorname{Ref}=$ no $)$ & \\
\hline & Yes & $1.1(0.66,1.87)$ \\
\hline & Nagelkerke R squared & 0.23 \\
\hline & Sample & 864 \\
\hline
\end{tabular}

${ }^{*} P<.05 .{ }^{* * P}<.01$

illnesses are not so serious. This may not only reduce the quality of primary care patients receive, but also a waste of health resources. Our study suggested that if there were a health policy guiding patients to use a USC, the overall quality of primary care might improve and the use of health resources could be more appropriate.

Our study also has implications for health care policy in Guangdong, where the proportion of surveyed patients without a USC was $56 \%$. Based on our study, the government should extent a USC policy, which may contribute to significant increases in quality of primary care. The advantages of USC can not only improve the quality of primary care, but also be conducive to the government in implementing health monitoring and health policy interventions, which may be especially good for the growing number of patients with chronic disease.

It is important to note that although the patients with a USC experienced higher quality of primary care in the community orientation domain, the scores of community orientation were still relatively low even for patients with USC. This suggests that community orientation needs to be improved in the provision of primary care.

There were a number of limitations in this study. First, this study was conducted in one region of China, therefore generalizability of the findings to other regions was restricted. Second, there might be underlying differences between patients who chose a USC and those who chose not to have a USC, which accounted for differences in perceived quality of care. Indeed, our study showed that USC and non-USC patient groups differed regarding age distributions, education levels, and presence of physical or mental problems. Although we controlled for these differences in our regression analyses, there might be other differences that remained unaccounted for. For example, patients who selected $\mathrm{CHCs}$ might prefer $\mathrm{CHCs}$ while the patients who went to tertiary hospitals might dislike CHCs. Third, this study examined patients' perceived quality of care experiences, rather than actual outcomes of medical care. Our study was a cross-sectional design, so it may be hard to make causal inferences.

\section{Conclusions}

In conclusion, this study added evidence that in China having a USC can provide higher quality of primary care to patients, which provides basis for health policy that promotes USC. Future studies may explore how to establish and promote the USC policy in China.

\section{Abbreviations \\ PCAT: Primary care assessment tool; USC: Usual source of care. \\ Competing interests \\ The authors declare that they have no competing interests.}

\section{Authors' contributions}

$\mathrm{RH}, \mathrm{CC}$, and $\mathrm{YH}$ conceptualized the study. ZD and YL carried out the analyses. $\mathrm{RH}, \mathrm{CC}, \mathrm{ZD}$ and $\mathrm{YL}$ drafted the manuscript. All authors read and approved the final manuscript. 


\section{Acknowledgements}

We wish to thank the Department of Health of Guangdong Province particularly Yurun Zhang, Hanping Yan and Ke Han for their support and coordination during the survey. This study was funded by Department of Health of Guangdong Province and Traditional Chinese medicine Bureau of Guangdong Province and approved by the Institutional Review Board of Sun Yat-sen University (Approval No.: IRB2014.9).

\section{Author details}

'Department of Medical Statistics and Epidemiology, Health Information Research Center, Guangdong Key, Laboratory of Medicine, School of Public Health, Sun Yat-sen University, 74 Zhongshan Road II, Guangzhou, Guangdong Province 510080, Peoples Republic of China. ${ }^{2}$ Department of health management, School of Public Health, Sun Yat-sen University, 74 Zhongshan Road II, Guangzhou, Guangdong Province 510080, Peoples Republic of China. ${ }^{3}$ Department of International Business, Ling Tung University, Taichung City, Taiwan 40852, R.O.C.

Received: 21 May 2015 Accepted: 17 July 2015

Published online: 31 July 2015

\section{References}

1. Starfield B. Is primary care essential? Lancet. 1994;344(8930):1129-33.

2. Damiano PC, Momany ET, Tyler MC, Penziner AJ, Lobas JG. Cost of outpatient medical care for children and youth with special health care needs: investigating the impact of the medical home. Pediatrics. 2006;118(4):e1187-1194.

3. Starfield B, Shi L. The medical home, access to care, and insurance: a review of evidence. Pediatrics. 2004;113(5 Suppl):1493-8.

4. Smith PJ, Santoli JM, Chu SY, Ochoa DQ, Rodewald LE. The association between having a medical home and vaccination coverage among children eligible for the vaccines for children program. Pediatrics. 2005;116(1):130-9.

5. Mainous 3rd AG, Hueston WJ, Love MM, Griffith 3rd CH. Access to care for the uninsured: Is access to a physician enough? Am J Public Health. 1999;89(6):910-2.

6. Li C, Dick AW, Fiscella K, Conwell Y, Friedman B. Effect of usual source of care on depression among medicare beneficiaries: An application of a simultaneous-equations model. Health Serv Res. 2011;46(4):1059-81.

7. Petterson SM, Rabin D, Phillips Jr RL, Bazemore AW, Dodoo MS. Having a usual source of care reduces ED visits. Am Fam Physician. 2009;79(2):94.

8. Safran DG, Karp M, Coltin K, Chang H, Li A, Ogren J, et al. Measuring patients' experiences with individual primary care physicians. Results of a statewide demonstration project. J Gen Intern Med. 2006;21(1):13-21.

9. Safran DG, Kosinski M, Tarlov AR, Rogers WH, Taira DH, Lieberman N, et al. The Primary Care Assessment Survey: tests of data quality and measurement performance. Med Care. 1998;36(5):728-39.

10. Schmittdiel J, Selby JV, Grumbach K, Quesenberry Jr CP. Choice of a personal physician and patient satisfaction in a health maintenance organization. JAMA. 1997;278(19):1596-9.

11. Shi L, Sun Y, Nie X, Meng Q. Job Satisfaction by Chinese Primary Care Doctors Following Health Care Reform. China Health Policy And Management Society. 2013;4(3):15-27.

12. Wei X, Zou G, Zhang H, Walley J, Liu Z, Newell J, et al. Implementation of the Chinese national microscopy centre policy: health facility survey in Shandong Province. Tropical medicine \& international health : TM \& $1 \mathrm{H}$. 2011;16(7):847-53.

13. Ji L, Newman J, Lu J, Cai X. Understanding the standard of care in the treatment of type 2 diabetes in China: results from a national survey. Chin Med J. 2014;127(20):3524-9.

14. Goldstein RB, Rotheram-Borus MJ, Johnson MO, Weinhardt LS, Remien RH, Lightfoot M, et al. Insurance coverage, usual source of care, and receipt of clinically indicated care for comorbid conditions among adults living with human immunodeficiency virus. Med Care. 2005;43(4):401-10.

15. O'Malley AS, Mandelblatt J, Gold K, et al. Continuity of care and the use of breast and cervical cancer screening services in a multiethnic community. Arch Intern Med. 1997;157:1462-70.

16. Rew L, Resnick M, Beuhring T. Usual sources, patterns of utilization, and foregone health care among Hispanic adolescents. J Adolesc Health. 1999;25:407-13.

17. Weiss GL, Ramsey CA. Regular source of primary medical care and patient satisfaction. QRB Qual Rev Bull. 1989;15:180-4.
18. Gill JM. Can hospitalization be avoided by having a regular source of care? Fam Med. 1997:29:166-77.

19. Sarver JH, Cydulka RK, Baker DW. Usual source of care and nonurgent emergency department use. Acad Emerg Med. 2002;9:916-23.

20. Lambrew JM, DeFriese GH, Carey TS, et al. The effects of having a regular doctor on access to primary care. Med Care. 1996:34:138-51.

21. Weinick RM, Drilea SK. Usual sources of health care and barriers to care, 1996. Stat Bull Metrop Life Insur Co. 1998;79:11-7.

22. Tsai J, Shi L, Yu WL, Lebrun LA. Usual source of care and the quality of medical care experiences: a cross-sectional survey of patients from a Taiwanese community. Med Care. 2010;48(7):628-34.

23. Shi L, Starfield B, Xu J, Politzer R, Regan J. Primary care quality: community health center and health maintenance organization. South Med J. 2003;96(8):787-95.

24. Yang H, Shi L, Lebrun LA, Zhou X, Liu J, Wang H. Development of the Chinese primary care assessment tool: data quality and measurement properties. Int J Qual Health Care. 2013;25(1):92-105.

25. Green LA. Science and the future of primary care. J Fam Pract. 1996:42(2):119-22.

26. Greenfield S, Rogers W, Mangotich M, Carney MF, Tarlov AR. Outcomes of patients with hypertension and non-insulin dependent diabetes mellitus treated by different systems and specialties. Results from the medical outcomes study. JAMA. 1995;274(18):1436-44.

27. Politzer RM, Yoon J, Shi L, Hughes RG, Regan J, Gaston MH. Inequality in America: the contribution of health centers in reducing and eliminating disparities in access to care. Med Care Res Rev. 2001:58(2):234-48.

28. Regan J, Lefkowitz B, Gaston MH. Cancer screening among community health center women: eliminating the gaps. J Ambul Care Manage. 1999:22(4):45-52.

\section{Submit your next manuscript to BioMed Central and take full advantage of:}

- Convenient online submission

- Thorough peer review

- No space constraints or color figure charges

- Immediate publication on acceptance

- Inclusion in PubMed, CAS, Scopus and Google Scholar

- Research which is freely available for redistribution

Submit your manuscript at www.biomedcentral.com/submit
C Biomed Central 